\title{
An analysis Seydan ecotourism with emphasis on sustainable development
}

\author{
Jamal Mohammadi $^{\mathbf{a}^{*}}$, Dariush Ahmadi ${ }^{\mathrm{b}}$ and Majid godarzi ${ }^{\mathrm{b}}$
}

\begin{abstract}
${ }^{a}$ Associate Professor of Geography and city planning, university of Isfahan, Isfahan, Iran ${ }^{b} \mathrm{PhD}$ student of Geography and city planning, university of Isfahan, ,Isfahan, Iran

\begin{tabular}{l}
\hline A R T I C L E I N F O \\
\hline Article history: \\
Received April 17, 2012 \\
Accepted 11 June 2012 \\
Available online \\
June 14 2012 \\
\hline Keywords: \\
Ecotourism \\
Tourism development \\
Seydan city \\
Natural attraction \\
SWOT model
\end{tabular}
\end{abstract}

\section{Introduction}

Ecotourism ('eco' as in ecological) is a kind of tourism founded based on a specific interest in the natural history of a particular region. The idea emerged out of the eco-development and sustainable development literature during the years of 1970s and 1980s and has generated a substantial amount of interest and controversy. Interest, since it represents an alluring alternative to the mass tourism paradigm, which has been very transformative to the social and ecological conditions of destinations throughout the world. In addition, it provides some controversial discussion since many feel that it has yet to live up to its position as a more responsible or ethical form of travel. Issues, which limit its ability to impact positive changes in society include links with more consumptive forms of tourism, like fishing and hunting; being subsumed by the much bigger mass tourism industry; the inability of local residence to control the scale and extent of development in their own regions; the profitability motivation; and new plans such as accreditation politicized and institutionalized (Fennell, 2009). Ecotourism supports environmental conservation, creates economic opportunities by emphasizing on benefits of the local community, and suggests that the involvement of the residents plays important

\footnotetext{
* Corresponding author. Tel: +98-311-7932037-8

E-mail addresses: j.mohammadi@ltr.ui.ac.ir (J. Mohammadi)

(C) 2012 Growing Science Ltd. All rights reserved. 
role for the efficient management of tourism. Despite the past 30 to 40 years of history, Weaver and Lawton (2007) suggest that ecotourism, as a field of academic inquiry, is still in a state of adolescence since there has been limited attention to critical areas such as the industry, quality control, external environments or institutions even as the components and issues of ecotourism are being extended.

Wu et al. (2010) evaluated the dimensions of urban ecotourism using the fuzzy number construction approach. The technique possesses different advantages, including an ability to cope with ambiguous issues such as comprehensive nature and the need for subjects to respond with a single number. The results of their method disclosed that economic factors played a lesser role than social and environmental factors did. The study also reinforced the relative importance position of community participation while promoting urban ecotourism. They reported data and findings extracted from two ecotourism destinations, one located in urban area and the other located in non-urban area. The findings indicated that "identifying with local culture" maintained the highest weight (7.19\%), followed by "inclination of supporting environmental conservation" (7.06\%), "satisfying local environment” (6.82\%), "the 5 degree of habitat diversity" (6.58\%), "inclination of urban ecotourism” (6.50\%), and "coverage of the green areas" (6.36\%).

Bunruamkaew and Murayam (2011) identified and prioritized the potential ecotourism sites using geographic information system (GIS) and analytical hierarchy process (AHP) in Surat Thani Province, Thailand. The study detected several factors for suitability within land ecosystems including landscape/naturalness, accessibility, wildlife, topography and community characteristics. The evaluation process for ecotourism site considered nine criteria including visibility, reservation/protection, land use/cover, species diversity, elevation, slope, distance from roads, proximity to cultural sites and settlement size. The factors were chosen based on the professional expert's opinions. AHP was efficiently implemented to evaluate the details of the factors and class weights. GIS is another important factor in ecotourism planning and the technique helped us identify ecotourism sites by linking the criteria deemed necessary with the actual resources of the Province.

Tsaur et al. (2006) utilized subjective figures to analyze the relationships between community, resource and tourism in sustainable ecotourism. They used a Taiwanese indigenous ecotourism site as a case study and used Delphi technique to identify evaluation indicators of this tourist destination. They interviewed many local residents, tourists and resource administration to explore each group's perception of relationships with the remaining two groups. Kara et al. (2011) made an assessment on the natural and ecological features of Kocarli Adnan Menderes Urban Forest with regard to the suitability for ecotourism. They suggest that continuity in public transportation will eliminate the problems of access and Kocarli Adnan Menderes Urban Forest is not only a very remarkable ecotourism area for people who live in Kocarli and near villages but also for people living in Aydın and other districts. They suggest that activities in Kocarli Adnan Menderes Urban Forest will help social and cultural improvement of the people and economic development of the region.

Zhang and Lei (2012) explored factors contributing to residents' participation intention in ecotourism management. They proposed a structural relationship between their participation intention, environmental knowledge, attitudes towards ecotourism and the appeal of tourist landscapes. The results indicated that residents' environmental knowledge positively influences attitudes towards ecotourism, which in turn directly and indirectly makes suitable decision to take part in ecotourism through their individual landscape affinity. Lu and Stepchenkova (2012) presented a quantitative technique for assessing ecotourism experiences reported online by U.S. travelers to Costa Rica. They applied the content analysis technique and 26 attributes, which impacted ecotourists' satisfaction with their ecolodge stays were determined and further aggregated into seven different categories including ecolodge settings, room, nature, service, food, location, and value for money. A two-step nonparametric statistical procedure was developed to quantitatively support the classification of attributes into satisfiers, dissatisfiers, criticals, and neutrals, the typology. 
Gurung and Seeland (2008) analyzed the current state of tourism in Bhutan and considered the prospects for the development of ecotourism. Empirical studies of tour operators and foreign tourists revealed that visitors interested in the natural beauty of the Himalayan kingdom stayed longer than those who came to experience its culture. By absorbing younger tourists, ecotourism could contribute to the objectives of gross national happiness. Most tourists and tour operators were in favor of ecotourism activities, which might benefit local rural communities. Chaminuka et al. (2012) analyzed the potential for development of ecotourism in rural communities adjacent to Kruger National Park (KNP) in South Africa. They determined preferences of tourists, according to origin and income levels, for ecotourism and their marginal willingness to pay (MWTP) for three ecotourism attributes including village tours, village accommodation and visits to crafts markets. They found out that among international and high-income groups of tourists, tourists were interested in paying much higher fees than proposed by communities.

In this paper, we present a survey on ecotourism in one of the most beautiful regions in Iran called Seydan located in south west part of Iran. The organization of this paper first demonstrates details of our proposed model in section 2. Section 3 explains details of our finding and concluding remarks are given in the last.

\section{The proposed model}

Seydan is located $65 \mathrm{kms}$ from shiraz-Isfahan road and it is only $12 \mathrm{~km}$ away from the largest work of history in country, Persepolis. This city is the gravity center of three ecotourism and historical places in Iran. Seydan has a very desirable climate and geographical situation. With beautiful and attractive natural perspectives promenades such as Ghasre Ghalat, Bodre garden, Sar Asiyab, Chehel Akhtaran, Derekhtan Chenar (plane trees), Hoze Mahi (fish pond), Hoze Ghom (ghom pond), Emarat Shahrdari (municipality building ), etc. are some of ecotourism and attractive places of Seydan. Fig. 1. shows geographical location of the city in the province of Fars.

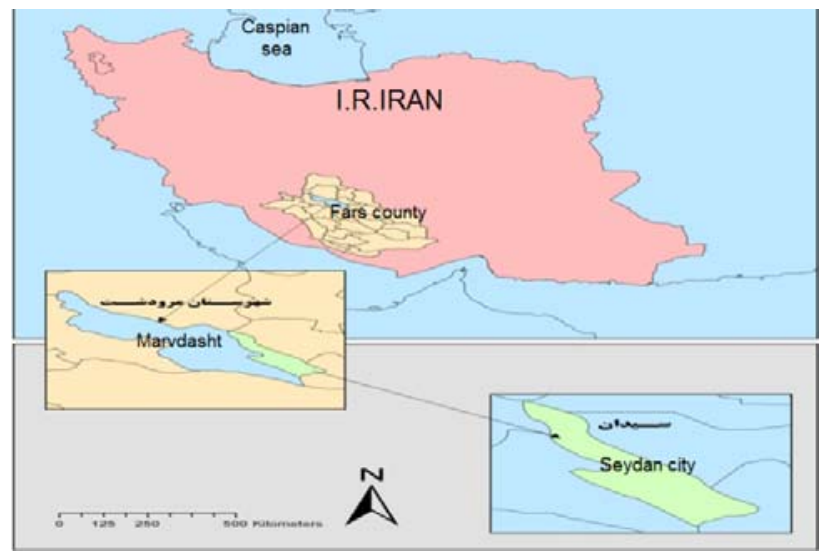

Fig. 1. Geographical location of Seydan

The primary purpose of this research is to investigate the existing potentials of ecotourism and to identify all threats surrounding the region and provide suggestions to remove the issues. It also proposes some guidelines for developing the ecotourism in this industry.

\subsection{Method and materials}

According to a report published by Seydan municipality there were approximately 100,000 people living in the region during the year of 2010. Using Kokran formula we have determined a sample of 400 people for this survey. 


\subsection{The main hypothesis}

The main hypothesis of this research paper examines whether environment ecotourism capabilities are more than other attractions. Therefore, the null hypothesis is as follow,

$\mathrm{H}_{0}$ : Environment ecotourism capabilities are not attractive compared with other regions.

There are some other sub-hypothesis associated with the proposed study of this paper as follows,

- Lack of knowledge and enough awareness of environment ecotourism attractions, was the reason for lack of regional ecotourism development.

- Empowering Seydan's ecotourism helps in development of the region.

\section{The results}

In this section, we present some of the detailed results of the questions we asked from our participants. Table 1 shows the summary of Chi-Square test.

\section{Test 1}

K square value and first hypothesis free degree:

\begin{tabular}{cccc}
\hline Test type & Amount & Free degree & Significant level \\
\hline K square & 248.100 & 3 & 0 \\
number & & 400 & \\
\hline
\end{tabular}

As we can observe from the amount of Chi-Square, the null hypothesis is rejected leading us to conclude that environment ecotourism capabilities are meaningfully attractive compared with other regions.

\subsection{Testing the second hypothesis}

The second hypothesis studies whether lack of knowledge and enough awareness of environment ecotourism attractions, was the reason for lack of regional ecotourism development or not. Table 2 shows details of our survey.

\section{Table 2}

The results of Chi-square test for the second hypothesis

\begin{tabular}{cccc}
\hline Test type & Amount & Free degree & Significant level \\
\hline K square & 120.334 & 4 & 0 \\
Number & 400 & 400 & 400 \\
\hline
\end{tabular}

\subsection{Testing the third hypothesis}

The third hypothesis investigates whether empowering Seydan's ecotourism could help in development of the region. Table 3 shows details of our survey.

\section{Table 3}

Chi-square test for the third hypothesis

\begin{tabular}{cccc}
\hline Test type & Amount & Free degree & Significant \\
\hline K square & 217.295 & 2 & 0 \\
Number & 400 & & \\
\hline
\end{tabular}


As we can observe from the results of Table 3, the null hypothesis is rejected when level of significance is set to five percent leading us to make a conclusion that empowering ecotourism in Seydan contributes to development of the region, significantly.

\subsection{Strategic Planning}

In this section we present strategic planning results performed in this survey to find out more about strength, weakness, opportunity and threats (SWOT). Table 4 shows details of our survey.

\section{Table 4}

The results of SWOT for Seydan ecotourism

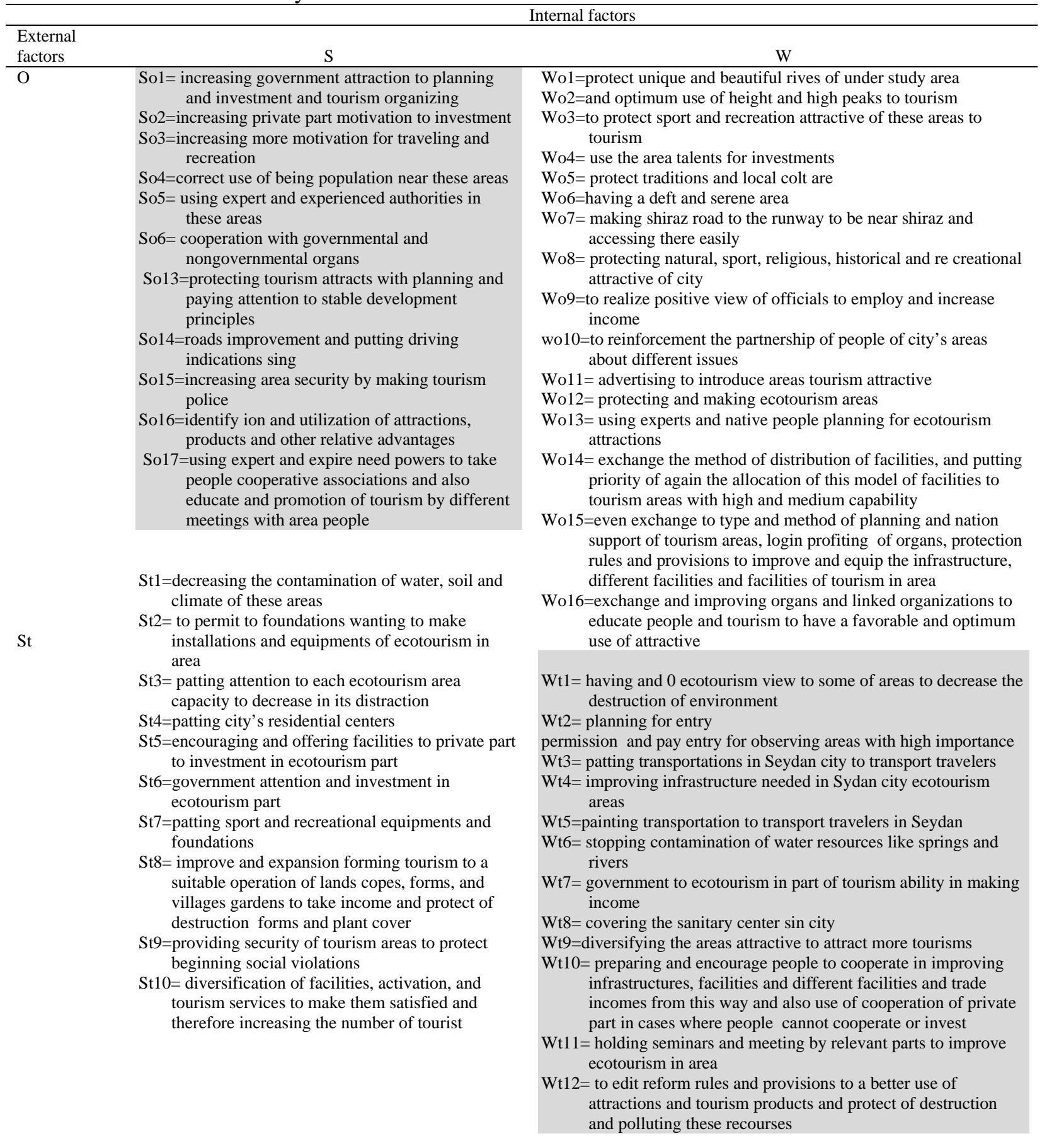




\section{Conclusion}

Nowadays ecotourism industry as the most wide extending industry in the world has a special position and many countries are in a close and compressed competition to attract more people to their own regions. The proposed study of this paper performed an empirical investigation to find out whether it is possible to attract more people in one of regions called Seydan located in south west of Iran. The proposed study distributed some questionnaire among 400 randomly selected residence and tried to find out whether investing more in the region could possibly contribute to ecotourism in the region or not. The results of our survey indicated that government must carefully concentrate on this region and invest more to create better facilities to attract more tourists. We have also performed strategic planning using SWOT to find out more about the treats, strength, weakness and opportunities surrounding the region.

\section{Acknowledgment}

The authors would like to thank all the people who participated in this survey and contributed their insight to enrich the content of this paper. We are also grateful to comments and suggestions provided by anonymous referees on earlier version of this paper.

\section{References}

Bunruamkaew, K., \& Murayam, Y. (2011). Site suitability evaluation for ecotourism using GIS \& AHP: A case study of Surat Thani province, Thailand. Procedia - Social and Behavioral Sciences, 21, 269-278.

Chaminuka, P., Groeneveld, R.A., Selomane, A.O., \& van Ierland, E.C. (2012). Tourist preferences for ecotourism in rural communities adjacent to Kruger National Park: A choice experiment approach. Tourism Management, 33(1), 168-176

Fennell, D.A. (2009). Ecotourism. International Encyclopedia of Human Geography, 372-376.

Gurung, D.B., \& Seeland, K. (2008). Ecotourism in Bhutan: Extending its benefits to rural communities. Annals of Tourism Research, 35(2), 489-508.

Kara, B., Deniz, B., Kilicaslan, C., \& Polat, Z. (2011). Evaluation of Koçarlı Adnan Menderes urban forest in terms of the ecotourism. Procedia - Social and Behavioral Sciences, 19, 145-149.

Lu, W., \& Stepchenkova, S. (2012). Ecotourism experiences reported online: Classification of satisfaction attributes. Tourism Management, 33(3), 702-712.

Tsaur, S.H., Lin, Y.C., \& Lin, J.H. (2006). Evaluating ecotourism sustainability from the integrated perspective of resource, community and tourism. Tourism Management, 27(4), 640-653

Weaver, D.B., \& Lawton, L.J. (2007). Twenty years on: The state of contemporary ecotourism research. Tourism Management, 28(5), 1168-1179.

Wu, Y.Y., Wang, H.L., \& Ho, Y.F. (2010). Urban ecotourism: Defining and assessing dimensions using fuzzy number construction. Tourism Management, 31(6), 739-743.

Zhang, H., Lei, S.L. (2012). A structural model of residents' intention to participate in ecotourism: The case of a wetland community. Tourism Management, 33(4), 916-925. 